\title{
The Plight of Male Child Care Workers in Taiwan
}

\author{
Hungchang Lee ${ }^{1, *}$ Chengchieh $\mathrm{Li}^{2}$ \\ ${ }^{1}$ Education Science College, Zhaoqing University, Zhaoqing, Guangdong, China. \\ ${ }^{2}$ Education Science College, Zhaoqing University, Zhaoqing, Guangdong, China. \\ *Corresponding author.Email: 3096305568@qq.com
}

\begin{abstract}
Taiwan society traditionally has stereotypical notions concerning the two genders. Gender differences in the structure of human physiology have led people of different genders to have different personalities, traits and behavioral patterns. It also has caused people to have different role expectations. People choose their jobs on the basis of what is gender appropriate. This then not only reinforces the stereotype, but also segregates by gender in the workplace. The current demand for nannies is mostly for married middle-aged working women. Male child care workers have to overcome many challenging obstacles. The difficulties faced by males who are engaged in babysitting jobs include the following: stereotypes arising from traditional social values, massive social pressure, scarcity of male workers, lack of parental confidence, low salary, many childcare incidents causing male childcare workers to have a low sense of accomplishment, low acceptance by family and friends, poor quality of life, loss of masculinity, and temporary or short-term career planning.

In facing this dilemma, the author recommends the following: promoting gender equality, increasing knowledge, sponsoring professional services, enhancing educational research, seeking support from friends, family and society, finding opportunities to build a reputation, increasing parental confidence by using modern technology, and encouraging everyone to do their best.
\end{abstract}

Keywords: nanny, childcare, gender roles, male worker

\section{INTRODUCTION}

Taiwan society traditionally has stereotypical notions regarding the two genders. Gender differences in the structure of human physiology have led people of different genders to have different personalities, traits and behavioural patterns. It also has caused people of different genders to have different role expectations. This then fortified the gender gap between men and women. It has indirectly shaped and strengthened our socio-cultural system as the basis of gender roles.

In a traditional tribal society, men must cope with the heavy expectations placed upon them. Because of their size and other physical characteristics, they must bear the difficulties of hunting. Meanwhile women are responsible for home care and other household chores. In addition, women have to bear the burden of having children, since this physical characteristic is limited to women. After the period of industrialization, a large number of women entered the labour market by providing cheap labour. Furthermore, because of their distinct personality and performance, women are more suitable for certain jobs.

Over the past decade, women have achieved higher education, and thus have a wider array of job opportunities. However, these opportunities are still limited by low wages, or even just household chores [1].in her study, women have been in a capitalist patriarchy. Even if women have escaped from prison, they are still constrained by another capitalist market.

In the beginning of the 20th century, due to sociocultural and institutional factors that influenced gender, Taiwan women were limited to certain occupations. This then formed the so-called "gender occupational segregation"[2]. As our society changes, double-income families are increasing. Now, there are more and more women who struggle with parenting as they work in the workplace. As society continues to develop, the role of working married women has increased. Traditionally, working mothers take care of their children. Now, they have been gradually seeking childcare services. Some mothers hand them over to elders, while others hand over their children childcare center or baby sitters.[3]. 
In addition, occupational bias has progressively narrowed the gap between the two genders. The data shows that the ratio of employment segregation between male and female fell from $68 \%$ in 1970 to $60 \%$ in 1980 , and further fell to 53\% in 1990[4]. For example, we can find male nurses in hospitals or male teachers in kindergartens.

People choose their jobs on the basis of what is appropriate for their gender. This then not only reinforces the gender stereotype, but also segregates by gender in the workplace. There are more and more people engaging in traditional work who are not part of gender-related occupations. This phenomenon has been slowly changing. However, according to relevant data, nurses, kindergarten teachers, and child care staff are considered to be traditional female occupations. As socio-cultural and educational level have advanced, gender bias has gradually changed. However, there are not a lot of Taiwan men who are engaged in or seem to want to work in childcare[5]. This then may be the reason for the problem. Below we will discuss the apparent reasons

\section{THE CURRENT STATUS AND ADVANTAGE OF BEING A MALE-CHILD CARE WORKER}

The current demand for nannies is mostly for married middle-aged working women. In 2018, there were only 8027 people qualified to receive babysitting licenses. Only 187 men were qualified, males comprise only $2.3 \%$ of the work force in Taiwan[6]. Lack of data suggests it may be even less. A woman is more naturally caring and loving toward children, and possesses innate gentleness. Therefore, women are most suitable for child care.

As we all know, it is the child care staff person to take care of children. Whether one is from the East or West, childcare is derived from the motherly role. Because women have been obliged to care for children, they have accumulated a lot of useful experience. There are more young women who rely on this skill to survive. Because childcare is a women's natural role.

In addition, gender role theory examines the general public's view of child caring, and specifically the stereotype of "child caring as a female job"[7]. In general, people agree that child caring is not suitable for men because it violates role expectations. As we all know, child caring is a woman's job. However, the term "child care staff" is not differentiated by gender. Before we discuss further the dilemma of being a male child care professional, it is necessary to explore the "probable" advantages of being a child care worker.

\subsection{Promoting the concept of equality with regard to gender roles}

Even if male child care professionals are few in number and are considered "unqualified" according to some valuable research, they may provide some positive effects on early childhood development. In sociology, both men and women have their own definite roles to play in society. For instance, when a male plays the role in child care, the public will exhibit a different perspective and attitude towards the men.

\subsection{Different parenting styles}

Females are dominant in the child care profession. The parenting styles of females' suit the behavioural patterns of children better. One possible challenge for female caregivers is the innate activeness of male children. The physical abilities of men are more prominent than those of women. From this perspective, men are more capable in facing the heavier duties of being a child caregiver. For example, this may include dynamic interaction with toddlers. In addition, men are often more active, lively, analytical, organized, and are better in handling high energy. Based on social learning theory, male child care workers can be role models giving children observational and other learning opportunities. From this point of view, the scarcity in male child care workers might possibly be an advantage because it makes them an object of discussion, thus, providing more options for families.

\section{CONCLUSION}

Objectively, male child care workers have to overcome many challenging obstacles. The outlook is pessimistic that male child workers can be brave in facing these challenges. Men who work in child care or in other so-called female occupations (such as nurses, kindergarten teachers) are under a lot of social pressure. Although there are a lot of government-related educational campaigns concerning the concept of gender equality, relevant social phenomena show that there are 10 difficult issues to resolve:

\subsection{Stereotypes arising from traditional social values}

Traditional stereotypes are the main reason why society is unable to accept the idea of male child care workers. Due to the conservative social atmosphere, it is not convenient for men to work in public as care givers. Society frowns upon men working in childcare industry. Society thinks that childcare is suitable for women only, and conflicts with men's character [8]. Traditional gender stereotypes make it difficult for men to find employment in other so-called "female" industries. Our society wishes 
for men to be ambitious in their career. Their career path must be in accordance with traditional culture value.

\subsection{Massive social pressure}

Generally, the term child care refers to a female occupation. "The job is mostly done by women, and the society does not expect men to engage in this kind of job" [9]. When a man takes part in a so-called female occupation, the general public tends to question his masculinity and work. Moreover, he has to undergo various trials to show whether or not he can perform on an equal level with a woman. This has led to much social pressure being placed upon male child care practitioners. Furthermore, societal expectations demand men be the head and main source of family income.

\subsection{Sparsity of male workers}

In Taiwan, data on the male of working population is insufficient. However, based on recent licenses, $1 \%$ or less child care workers are male. Of this $1 \%$, only a few actually work as child caregivers. Some of them only assist, or leave the profession to become fathers. A probable reason on why there are so few male child caregivers is because the general public is not supportive of the idea. Men, compared to female child care workers, work mostly part-time jobs. So oftentimes, the couple looks after two or more children together. Male child care workers tend to already be married, older and more experienced.

\subsection{Lack of parental confidence}

The general public's perception is that "women are more qualified to care for children" Women are better suited for the challenges of this role. [10]. Even parents of young children and infants believe it is proper for women to take care of their children. They are worried about male child care workers not being careful enough, not demonstrating enough loving care, and exhibiting rude behavior. In addition, there are many parents who question male child care workers' masculinity since it could lead to gender identity issues for the children. Indeed, sexual harassment and abuse will always be an issue.

Parents have hidden suspicions towards male child care nannies or teachers. They feel that male child care workers are dangerous. The underlying reasons for their hesitation are male inability, sexual orientation, and motivation for being workers.

\subsection{Low salary}

In general, parents want their children to have a "more promising career"(especially boys). Besides, child care offers low wages and does not bring one higher socioeconomic status. Therefore, most parents think there is no future in this job. In addition, experienced people know that being a child care worker is a tedious and interminable job. Furthermore, parents hope their children "do less work, earn high wages and work close to home" In most people's eyes, occupations such as child care, kindergarten teachers, nurses, secretaries and such have always been a woman's job. These jobs generally offer a low salary, low opportunity for promotion, and limited opportunity to exercise power. This then necessitates that men be breadwinners for their family. Therefore, most men are not attracted to the idea of becoming child care workers.

\subsection{Many childcare incidents cause male childcare workers to have a low sense of meager}

For parents, childcare safety is most important. Negligence causes serious harm, as Chang notes: Injuries occurring frequently in children under 5-years-oldare the greatest pressure source for male childcare workers[11]. Studies show that male child care workers will stay in feminine occupations if they have a sense of accomplishment [12], but unexpected accidents cause male childcare workers to lose this sense of accomplishment.

\subsection{Low acceptance by family and friends}

Parents usually have higher expectations for their male offspring. When a single man decides to become a child care worker, there is usually resistance from family and friends. Although a new generation in Taiwan society has already accepted the concept of equal rights, the older generation still hesitates. They think a child care worker does not require many skills. Any female can do the job. In addition, male child care workers need their families' trust and love in order to succeed in their vocation. However, it seems that their families do not provide this kind of support.

\subsection{Poor quality of life}

According to Yang \& Hu the majority of childcare workers provide mainly 8-12 hours a day of care, and $42 \%$ of the staff work 51-60 hours per week[13]. The working hours are much longer. Secondly, compared to other industries, different kindergartens have different compensation packages. And benefits in public kindergartens are better than those in private kindergarten.

In addition, male childcare workers are a better choice if there is a need to move heavy objects, or if physical labor is required. Long working hours, lower salary and unpredictable job description, not only affect the quality of life, but also affect morale. 


\subsection{Loss of masculinity}

Men who are engaged in female occupations tend to be questioned whether they are masculine or "man enough" [14]. Based on related research, men who engage in female occupations may have gender identity issues[15]. Having to work in a female occupation makes a man feel less masculine. Men must stay away from female jobs in order to avoid suspicion. Just as Cross and Bagilhole point out in their study, males should avoid engaging in female occupations since they will be considered to lack masculinity[16]. Our society wishes men to be ambitious in their careers. They are expected to match their performance with traditional values and ability. There is often a negative stereotype when men engage in female professions.

\subsection{Temporary or short-term career planning}

Wang \& Lai point out that the salary of workers in child care institutions ranges from about $\$ 420-\$ 620$ [17]. However, heavy workloads result in high turnover. Lu \& Yen note that being a worker does not require special skills[18]. Anyone temporarily unemployed can become a childcare worker. For instance, they will receive questions from the general public: "Why would you work as a child care worker?" Aspiring male child care workers should not rush into this kind of work environment since it will result in excessive social pressure.

\section{RECOMMENDATIONS}

A comprehensive seven points analysis:

\subsection{Gender equality and knowledge}

"Education" is the key to cultural reconstruction or improvement. Gender equality can be introduced and promoted into a new culture by education. Rebecca, Hefner \& Oleshansky argue that as the concept of gender equality develops, individual behaviors are no longer bound by traditional gender roles[19]. Men who engage in these female occupations will suffer judgement. Positive feedback will help the concept of gender equality and negative feedback will obstruct gender equality.

\subsection{Promoting professional service}

Professional child care workers should not just be "really good in taking care of children" professionally, but should be professional experts. Moreover, they should know how to guide children through different developmental stages. Our "professional" labor era is different from the experienced-based labor of the past. If only male nannies could have a more extensive parental experience, and be equipped with professional knowledge (eg. through professional training courses), then they would be more prominent in their field.

\subsection{Enhancing educational research}

In addition, investing in academic research helps provide a new perspective on some issues and promotes understanding. Research provides new insights into worker-related issues, as well as gender equality. Also, this research can educate the male care-giver about the male-nanny situation.

\subsection{To seek support from friends, family and society}

Friends and family will not only affect career choices, but also help male child care workers to feel supported. Furthermore, colleagues will provide additional emotional Support.The salary is low, but the mail child worker feels good because of the support the family and friends provide. Thus, workers will not feel isolated, but rather feel they are valued members of the community. Studies point out that social support and individual health, happiness, and life adaptation have a very positive association[20].

\subsection{Find an opportunity to build a reputation}

A well-balanced society allows people to pursue whatever is suitable for their development, and will not treat them differently just because of gender. The current working population has less than one percent of men in an almost all-female industry. We must address this situation.

Secondly, being a child care worker has been regarded as a woman's job, since most workers are women. More male nannies will break the stereotype, enabling childcare work to be regarded as a professional industry. Therefore, a feasible strategy is to introduce men through media who can do a good job as child care workers By doing this, society will gradually grasp the concept, and child care workers, kindergarten teachers and care workers will have more opportunities available for them to take care of children.

\subsection{Increase parental confidence by using modern technologies}

In general, men are better at using technology. Male nanny can use audio-visual media and cameras to help parents so that parents can keep abreast of their children every day. This will give parents more confidence.

\subsection{Try to do their best}

Those who want to enter a gender-specific profession will have to undergo an examination of their legitimacy. Men who want to become child care workers will be 
victims of parents reacting violently. The general public will be curious with regard to this issue and ask questions like: "How men engage in this job?" "How do they regard the community's opinion?" "How would you adapt?" With this kind of situation, the only thing to do is to "face it, and deal with it." Problems faced by male nannies such as social stress, lack of parental approval, and few workers cannot be solved overnight. Even if the government exerts its influence, male child care workers should only focus on doing their duties and to think of themselves as "fathers of the children in the kindergarten classroom." They should be able to handle the children, clean them up, and provide medicine as needed. Although gender stereotypes have deep historical roots, they will gradually loosen over time.

\section{REFERENCES}

[1] H. Bradley, Men's work, women's work: A sociological history of the sexual division of labour in employment. Minnesota: University of Minnesota Press, 1989.

[2] C. F. Chang, Bringing the culture back in: The gendered processes within institutions and structures in Taiwanese labor markets. Taiwanese Journal of Sociology, Vol. 29, pp. 97-125, 2002.

[3] [10] H. Y. Duan, S. L. Yang, and T. C. Hsiao, Retrospect and prospect of family Child care services in Taiwan. Journal of Child and Youth Welfare, Vol. 20, pp. 69-87, 2012.

[4] J. P. Jacobsen, Sex segregation at work: Trends and predictions. Social Science Journal, Vol. 31, pp. 153-168, 2, 1994.

[5] Y. S. Ou, Nanny daily wage is up to 300 yuan, higher educated nanny worked on it. Wenzhou Evening News. 2015, Retrieved from http://news.66wz.com/system/2015/01/26/1043404 34.html

[6] Workforce Development Agency. The ratio in terms of the qualified male nannies. 2019 Retrieved from http://statdb.mol.gov.tw/html/sex/8010.htm

[7] S. A. Basow, Gender: Stereotypes and roles. Pacific Grove: Brooks/Cole, 1992.

[8] P. Abbott, M. Tyler, and C. Wallace, An introduction to sociology: Feminist perspectives. London: Routledge and Kegan Paul, 2005.

[9] C. L. Williams, The glass escalator: Hidden advantages for men in the "female" profession. Social Problem, Vol. 39, pp. 253-267, 1992.

[11] M. D. Chang, Health awareness and first aid in conditions. Early Childhood Education, Vol. 15, pp. 19-21, 7, 1993.
[12] H. S. Chang, .From inexperience to maturity: A narrative inquiry into a male social worker's gender experience at work. Unpublished master dissertation, National Taiwan University. Taipei. 2005.

[13] H. L. Yang, \& C. Y. Hu, A study of childcare quality of licensed family child Care providers in Taipei city. Journal of Child and Youth Welfare, Vol. 8, pp. 1-32, 2005.

[14] [18] T. S. Lu, and . C. Yen, A male kindergarten teacher's construction and positioning of the sex role. The Journal of Study in Child and Education, Vol. 1, pp. 1-21, 2005.

[15] [16] S. Cross, and B. Bagilhole, Girls' jobs for the boys? Men, masculinity and non-traditional occupations. Gender, Work and Organization, Vol. 9, pp. 204-226, 2002.

[17] S. Y. Wang, and H. Y. Lai, Child care difficulties and role of the state in Taiwan. In Y. S. Liu(Ed.), Women, countries, and care services, Taipei: Fembooks, 1997, pp. 127-159.

[19] M. Rebecca, R. Hefner,and B. Oleshansky, A model of sex role transcendence. Journal of Social Issues, Vol. 32, pp. 197-205, 3, 1976.

[20] M. H. Wei, The study of well-being of kindergarten's teachers. The Journal of Educational Science, Vol. 10, pp. 173-194, 2011. 